\title{
28 Research Square \\ Failed implementation of mobile access to electronic health records in homecare: a qualitative study
}

Lovisa Jäderlund Hagstedt ( $\sim$ Lovisa.jaderlund.hagstedt@ki.se )

Karolinska Institute

Helena Hvitfeldt

Stockholm County Council

Maria Hägglund

Uppsala University

\section{Research Article}

Keywords: mEHR, mobile, homecare, primary care, work environment, CFIR, mHealth, eHealth, implementation

Posted Date: May 27th, 2021

DOI: https://doi.org/10.21203/rs.3.rs-558554/v1

License: (c) (1) This work is licensed under a Creative Commons Attribution 4.0 International License. Read Full License 


\section{Abstract}

\section{BACKGROUND}

Digitalization could optimize healthcare; however, many eHealth projects are unsuccessful. By analyzing reasons for unsuccessful eHealth implementation, we could gain important knowledge on how to achieve successful digitalization in primary care and homecare.

The aim of this study is to describe the implementation process of a tablet computer with an mHealth app that provides mobile access to the electronic health record (EHR) in homecare in order to understand reasons for unsuccessful implementations of mHealth interventions, as well as potential success factors.

\section{METHODS}

A tablet computer with mobile access to the EHR was implemented in 4 primary care centers and one municipality home care organization in Sweden. Focus groups, interviews and observations were used to evaluate how the implementation affects the work of the healthcare professionals. Qualitative content analysis informed by the Consolidated Framework for Implementation Research was used to analyze the implementation process and interpret the results.

\section{RESULTS}

The implementation of the eHealth application was unsuccessful, mainly because the application did not fully support the users' needs, but also due to immature technology and unstable infrastructure. Outcome of the intervention was dependent on context and user engagement. Users who had been involved in the development were more positive, despite missing functions, whereas those who had not been involved struggled to adopt the mobile tool. Development of the mHealth app and the subsequent implementation process was lengthy which affected user engagement negatively. The implementation process was insufficient and use of the application was affected by poor readiness for implementation. Users perceived lack of leadership engagement and questioned available resources dedicated to the implementation, in terms of resources and training.

\section{CONCLUSIONS}

The functionality of mHealth must support users' needs, be sufficiently integrated with existing eHealth ecosystems, and all aspects of the implementation process must be met to ensure success. Premature implementations may cause change fatigue and become a barrier for future implementation projects. In order to achieve the potential of mHealth, we have to ensure that sufficient resources are allocated to design and development, evaluation and feasibility studies and support and engagement during the implementation of mHealth in the future.

\section{Background}


As populations age, the need for primary care and homecare increases [1], yet resources remain scarce with serious recruitment challenges [2]. According to the Swedish Association of Local Authorities and Regions (SKR) future healthcare will need to be provided closer to the patient and digitalization, a holistic approach and an improved collaboration and availability of care will be necessary [3]. Electronic health records (EHRs) are used in everyday care throughout Sweden [4]. Most of the county councils and regions use one EHR system throughout hospitals, primary care and psychiatric care, which means the patient records are available in the entire region. Elderly care is however, the responsibility of municipalities, falls under a different legislation [5], and often uses separate EHR systems [6]-[8]. Private healthcare providers may also use different systems which means the information access can be limited, even though many regions have an agreement with private actors, which allows information exchange [4].

The concept mHealth has emerged as a sub-category of eHealth and can be defined as medical and public health practice supported by mobile devices [4], [9]. The use of smartphones and tablets in healthcare is increasing and currently, seven (out of 21) Swedish regions have strategies for the use of tablets, and use tablets in care-providing activities (e.g. to provide mobile access to medical records) [4]. The extent of implementation of mHealth solutions in homecare within these seven regions is however not known. The use of mobile devices for home care has increased in the Swedish municipalities as well; in $17 \%$ of the municipalities, healthcare staff have the possibility to read and write information using a mobile device, compared to $5 \%$ in 2015 and $11 \%$ in 2016 [10].

Further digitalization and introduction of eHealth and mHealth has been seen as a means to optimize healthcare and expectations are high that it will be the solution to many of the problems that exist in healthcare today [11], but unfortunately many projects are unsuccessful [12] and challenges of digitalization have been raised [13]. There are several reasons that explain why implementations of eHealth in healthcare fail [14], [15]. By studying and analyzing the underlying reasons of why an eHealth or mHealth implementation is unsuccessful, we could gain important knowledge on how to achieve successful digitalization in primary care and homecare in the future.

\subsection{Factors contributing to implementation success}

In the area of video consultations, potential enablers of spread and scale-up included embedded leadership and the presence of a telehealth champion, appropriate reimbursement mechanisms, userfriendly technology, pre-existing staff relationships, and adaptation (of technology and services) over time. Challenges tended to be related to service development, such as the absence of a long-term strategic plan, resistance to change, cost and reimbursement issues, and the technical experience of staff [16].

In a Cochrane review of mHealth applications it was shown that the complexities of healthcare delivery and human interactions defy simplistic conclusions on how health workers will perceive and experience their use of mHealth. Perceptions reflect the interplay between the technology, contexts, and human attributes. Detailed descriptions of the program, implementation processes and contexts, alongside 
effectiveness studies, will help to unravel this interplay to formulate hypotheses regarding the effectiveness of mHealth [17].

For eHealth to fulfill its promise in primary care, stakeholders need to be involved in the development and implementation of eHealth via co-creation processes, and design should be mindful of vulnerable groups and eHealth illiteracy [11]. This is also true for mHealth solutions, with the added complexity of mHealth being used in different contexts with constraints with regards to e.g. internet connectivity, screen size and work processes.

This study was originally designed to evaluate a mHealth application, that provides healthcare professionals with mobile access to the EHR and describe its impact on work processes and work environment. The project was however terminated prematurely since healthcare professionals did not adopt and use the system. The collected data will therefore be analyzed to understand the reasons for the implementation failure.

\subsection{Aim}

In this study, we aim to describe the implementation process of a tablet computer with an mHealth app that provides mobile access to the EHR in home care in order to understand reasons for unsuccessful implementations of mHealth interventions, as well as potential success factors. We will use the Consolidated framework for implementation research (CFIR) by Damschroeder et al [18], to guide our analysis.

\section{Methods}

A qualitative approach has been applied to understand the implementation process as well as the healthcare professionals' experiences of using the system. Individual interviews, focus group interviews and observations have been used to obtain a rich understanding of the implementation related issues.

\subsection{Study setting}

The study was conducted within Tiohundra AB in Norrtälje, the largest municipality in the northern part of Region Stockholm, Sweden. The implementation took place in the municipality home care organization (MHCO), as well as in the home care sections of four primary care centers (PCC) whereof one located on the island Djurö. All of the PCCs are affiliated to the Region Stockholm healthcare organization. The $\mathrm{MHCO}$ has the main responsibility for homecare, but PCCs provide some homecare (e.g. the first two weeks after a patient has been discharged from hospital, and support and service for persons with certain functional impairments).

The PCCs all use one EHR system, which was made accessible through the mHealth app, whereas the MHCO used a different EHR system which was not accessible through the mHealth app. An overview of the study setting is presented in Figure 1. 
All of the participating units constitute sparsely populated island regions with vast geographical distances and an aged population causing a great need for home care.

\subsection{Study participants}

Participants in this study were mainly nurses, but also physicians working in either the home care section of the PCCs participating, or the MHCO. Eight nurses and one physician from the PCCs and eight nurses and one physician from the MHCO participated in the study (Figure 1).

\subsection{The intervention}

The intervention consisted of two parts; (1) a tablet device with several already existing applications e.g. decision support, online prescription tools and the possibility to order supplies online, and (2) the new mHealth app giving mobile access to the EHR. In the following text, we will refer to the latter as "the mHealth app", and use the term "the mobile tool" when referring to the tablet with all its applications.

The mHealth app on the tablet computer was developed after an initiative by professionals at one of the participating primary care centers. They saw a need for easy access to information, including patient data, and to be able to carry out all parts of their home care work, including documentation, while being in the patient's home. From their ideas the mHealth app was developed. The first author was involved in some of the needs and requirement analysis of the app.

The mHealth app provided mobile access to the EHR used in regional home care. Due to technical difficulties, not all parts of the EHR were accessible by the mHealth app. It was not possible to access information on patients' medications, referrals or radiology results. However, it was possible to access information on the patients' previous outpatient and inpatient care visits, diagnoses and laboratory tests. Thereby, some, but not all of the healthcare professionals' needs were met by the mHealth app.

The tablet computer also provided access to several clinical decision support systems and a mobile webbased prescription system that is used for some of the patients in home care, thus enabling the healthcare professionals to manage part of those patients' medications.

Thereby, the diverse functions of the tablet computer provided the healthcare professionals with a multifaceted mobile tool for home care visits.

The mobile tool was first implemented in the home care section of the PCC that was part of the development of the mHealth app and in one of the other PCCs. In both of the participating PCCs where the mobile tool was first implemented, some of the healthcare professionals were avid advocates for the mHealth app.

At a later stage, the mobile tool was implemented in the $\mathrm{MHCO}$ and in the remaining PCCs. There were no advocates for the mHealth app at either of these workplaces.

\subsection{Data collection}


Data for this study was collected through focus groups and semi-structured interviews with nurses and doctors working in home care where the mobile tool was introduced, and through observational studies of nurses and doctors using the mobile tool. The first author had the main responsibility for the data collection, with the assistance of two master students. An overview of the timeline and data collection is presented in table 1. An initial workshop was held where questions were asked regarding the time spent on administrative work related to home visits, experienced stress, use of decision support tools and experienced quality of documentation and communication between healthcare professionals. Prior to implementation, focus group interviews were held where the project was introduced, the mHealth app demonstrated and the positive and negative expectations were discussed and reflected upon by the different healthcare professionals that would use the mobile tool.

Participatory observations were performed to capture aspects around the daily use of the mobile tool that otherwise may be difficult to report on in retrospect. Focus of the observations were on how the mobile tool was being used during, between and after patient encounters. The observing researcher kept notes during the observations.

\section{Table 1 - Overview of the data collection timeline}

\begin{tabular}{|c|c|c|c|c|c|c|}
\hline Data collection & PCC1 & PCC2 & РCC3 & PCC4 & $\begin{array}{l}\text { Home } \\
\text { Care } 1\end{array}$ & $\begin{array}{l}\text { Home } \\
\text { care } 2\end{array}$ \\
\hline $\begin{array}{l}\text { Development of } \\
\text { application }\end{array}$ & $\begin{array}{l}2014- \\
2015\end{array}$ & - & - & - & - & - \\
\hline $\begin{array}{l}\text { Focus group on } \\
\text { expectations }\end{array}$ & $\begin{array}{l}\text { November } \\
2015\end{array}$ & $\begin{array}{l}\text { May } \\
2016\end{array}$ & $\begin{array}{l}\text { April } \\
2017\end{array}$ & $\begin{array}{l}\text { April } \\
2017\end{array}$ & $\begin{array}{l}\text { April } \\
2017\end{array}$ & $\begin{array}{l}\text { May } \\
2017\end{array}$ \\
\hline Individual interviews & May 2016 & $\begin{array}{l}\text { February } \\
2017\end{array}$ & $\begin{array}{l}\text { February } \\
2018\end{array}$ & $\begin{array}{l}\text { March } \\
2018\end{array}$ & $\begin{array}{l}\text { February } \\
2018\end{array}$ & $\begin{array}{l}\text { February } \\
2018\end{array}$ \\
\hline Observations & May 2016 & - & $\begin{array}{l}\text { February } \\
2018\end{array}$ & $\begin{array}{l}\text { March } \\
2018\end{array}$ & $\begin{array}{l}\text { February } \\
2018\end{array}$ & $\begin{array}{l}\text { February } \\
2018\end{array}$ \\
\hline $\begin{array}{l}\text { Focus group on } \\
\text { completion of study }\end{array}$ & $\begin{array}{l}\text { October } \\
2016\end{array}$ & - & - & - & - & - \\
\hline
\end{tabular}

Individual interviews were performed to capture the staffs' experiences of using the mobile tool and its impact on work processes. Both physicians and nurses were interviewed.

Interview guides were developed for both individual and focus group interviews (see Appendix 1-3). All interviews and focus groups were recorded and transcribed. Notes were also taken during focus groups and included in the material. All interviews were held in Swedish. The individual interviews lasted 20-30 minutes, and the focus group interviews 1-1.5 hour.

Observations and interviews were performed after the mobile tool had been used for at least 6 months and were conducted by the first author and master students in the research team. 
The PCC that was involved in the development of the mHealth app started testing earlier than the other clinics, and a focus group interview was held a year after they started using the mobile tool to capture their long-term experiences. When interviews and observations were performed at the other clinics, they had stopped using the mobile tool and it was deemed unnecessary to do additional focus group interviews.

Ethical approval for this study has been granted from the Research Ethics Committee at Karolinska Institutet (DNR 2015/1457-31/5).

\subsection{Data Analysis}

All interviews were transcribed and analyzed using a deductive content analysis approach [19]. CFIR was used to structure the analysis.

CFIR identifies 5 dimensions that are essential to implement an intervention [18];

1. intervention characteristics (e.g., evidence strength and quality);

2. outer setting (e.g., regulations and resources);

3. inner setting (e.g., culture, leadership engagement);

4. characteristics of individuals (e.g. skills, values, knowledge, motivation); and

5. process (e.g., plan, evaluate and reflect).

An overview of the CFIR dimensions and their subheadings is presented in Figure 2.

The three authors all actively participated in the analysis. Initial coding was performed by LJH, MH and a research assistant participating in the study. First all materials were read and re-read and meaning bearing units were identified. The meaning bearing units were coded individually by each coder and categorized to one of the five dimensions from the CFIR framework. $\mathrm{HH}$ joined the analysis at this stage and the three authors discussed the coding until consensus was reached on the interpretation of the results.

\section{Results}

Using the five domains of CFIR, we present our analysis of the healthcare professionals' expectations before implementation, and experiences during the implementation of the mobile tool. We identify the key barriers causing the implementation to fail and aspects that had a positive influence.

\subsection{Intervention characteristics}

Before the implementation, healthcare professionals' expectations were high, yet the interviews after 3 and 6 months of using the application revealed that many of the expectations were unmet. Figure 3 
presents an overview of the categories related to the characteristics of the intervention, and more details from the qualitative analysis are presented below.

\subsubsection{Expectations before the implementation}

Healthcare professionals had both high hopes that the mobile tool would support their work, and serious concerns that the technology would not meet their expectations.

Relative advantage

During the pre-implementation focus group interviews, the healthcare professionals expressed high expectations that the new mobile tool would help reduce their cognitive workload by allowing them to complete tasks (e.g. ordering materials or sending referrals) and finish documentation in the field.

To be able to complete the documentation before leaving the patient's home. It would be a dream. You forget so much on the way back to the office.

The real time access to information would make it possible to make more informed decisions and reduce the need to call colleagues to find information from e.g. the EHR. However, there were also concerns, "It's faster to write a post-it note. If it [the mobile tool] doesn't provide everything we need, it may end up in the office". Staff already knew that some important functionality (e.g. the medication list and referrals) would not be available, and concerns were that this would limit the usefulness of the application. "Frankly, it feels a bit underdeveloped. There are several things that are missing, like the medication list and $x$-ray results, which is also quite important when you visit the patient and need to discuss prior events or future plans."

\section{Complexity}

There were also concerns that missing functionality would result in workarounds and the need for double documentation that might increase the administrative and cognitive workload, especially concerning medications and lack of necessary templates in the medical record. "Above all, I would like to have access to the medication list. I know that it won't be included, but it would make my job so much easier since I organize the patients' pill box dispensers in their homes."

\section{Design quality}

Prior to the implementation there were some apprehensions regarding the maturity of the system and that it might be slow and frustrating; "...that the software is only half-developed and not fully functional." Several of the healthcare professionals were worried that the testing would be hampered due to immature technology; "If it's malfunctional you won't use it much."

\subsubsection{Experiences of the intervention}


The semi-structured interviews and observations showed that the needs and requirements of the users were not sufficiently met by the mobile tool, largely because the mHealth app was not sufficiently adapted to the users' needs. There was, however, a significant difference between how the mobile tool was perceived by the healthcare professionals that worked where the intervention was first implemented, who had taken a more active role in the needs analysis and requirements specification, compared to those working where the intervention was later implemented. Those that had been involved in the development of the mHealth app and were part of the initial implementation considered the application to be much more useful than those who had not been part of the development of the application.

\section{Relative advantage}

Patient visits have become more complete, new questions that arise can be answered quickly."The healthcare professionals experienced that the mobile tool facilitated work processes and that it was fulfilling to be able to immediately answer questions from patients. Another positive effect of the intervention was that it reduced the cognitive workload. "I don't need to bring notes that I will later have to remember to document separately on every patient.

However, not all needs and requirements were met. The concerns about missing functions that were expressed prior to the implementation was confirmed. "Well, I would use it so much more if it was more functional. You could say it's very limited as it is now."

\section{Complexity}

The limitations in functionality, with missing templates, lack of dictation functionality as well as technical challenges with the smaller keyboard on the tablet computer proved to be a confining factor. "The templates are a bit too, well...wrong. So it becomes so very limited, and then it feels like it's easier to take notes by hand."

Many of the healthcare professionals also felt that their documentation became more condensed and that the documentation done on site was preliminary and had to be further developed when they had returned to the office; "The documentation may be a little shorter, sometimes the record entries become shorter." For some of the staff the limitations in documentation functionality resulted in them not using that at all.

"And still, for me it is faster to dictate than to write. So I do not write any record entries in the app. I use it to read record entries when I'm in the patient's home. Then it works well for the most part"

\section{Design quality}

The users were not impressed by the application's layout, especially concerning the design of the laboratory results. "But you get for example all of the hemoglobin results one after the other. It's terribly difficult to read. Seven or eight rows of results for each blood test." The users did however, feel that the 
design improved somewhat during the project, "I found it worse in the beginning when there were only fixed settings and not possible to enter your own text."

Most of the healthcare professionals experienced difficulties with the functionality and deemed the application immature and unstable.

Sometimes the internet connection has been bad. Sometimes the application has not worked despite adequate internet connection. It has happened that I have been able to access the system for the medical record, I have been able to find the specific patient's medical record, but then it just stops working. I tap and tap but nothing happens. That's it.

Another user expressed "All too often it has not worked. Either the internet connection has been inadequate or there is no explanation as to why I can't log in."

\subsection{Outer setting}

Since the CFIR was not developed for studying implementations of eHealth, we found that there was a need for an additional category in the outer setting domain. Technical infrastructure, such as functioning network connectivity is paramount when mHealth and eHealth solutions are implemented. Without functioning network connectivity the mobile tool would be useless. Therefore, we chose to include Technical infrastructure as an additional category of Outer setting. In this domain the expectations of the intervention, to a large extent, coincided with the actual experiences of the intervention. Figure 4 gives an overview of the categories identified in the outer setting dimension.

\subsubsection{Expectations before the implementation}

Healthcare professionals were expressing concerns regarding the Internet connectivity in the area, but were also looking forward to using the mobile tool to meet the needs of their patients.

\section{Technical infrastructure}

Network connectivity is limited in parts of the rural areas of the study setting and since many of the healthcare professionals had previous experiences with problems due to poor internet connectivity, concerns were expressed prior to the implementation. "The fear is the network connection. That's the thing, and it's hard to solve."

\section{Patient needs and resources}

Healthcare professionals were hoping that the mobile tool would enable them to improve patient communication and participation by using it as both a tool for learning, "And you may be able to show patients how to easily access sites for healthcare e-services", and a means to answer questions asked by the patient, "Medical record entries may be useful when you're in the patient's home. - What did the doctor say at the last visit? I did not understand" 


\subsubsection{Experiences of the intervention}

The healthcare professionals' expectations regarding the outer setting were fulfilled to a large degree.

\section{Technical infrastructure}

The limited network connectivity proved to be a real challenge when using the mobile tool. One of the users stated: "Our damn bad network connection has proven to be a huge, huge problem."

\section{Patient needs and resources}

The staff experienced that the mobile tool supported better work processes and thereby improved patient safety; "communication with the patient runs smoother due to the fact that I'm able to answer questions on site, e.g. concerning lab results." However, when the mHealth app did not work, it also sometimes rendered other, less positive questions from patients; "personally, I've appreciated being able to answer a question that the patient has asked. But sometimes you have to answer other questions as well, when the application doesn't work. - But if it does not work, why do you use it? The patient asked me one day."

\subsection{Inner setting}

Healthcare professionals experienced that the mHealth app was not adapted to their workflow and therefore the mobile tool was not seen as entirely useful. This was especially apparent in the MHCO, and for the participating physicians. There were also implications that the implementation process would have benefitted from a stronger commitment from the organization and some of the healthcare professionals experienced that there was not enough time for training and preparation before the implementation. Figure 5 gives an overview of the categories in this dimension.

\subsubsection{Expectations before the implementation}

Inner setting was not discussed much during the pre-implementation workshops, and mostly concerns were raised.

\section{Structural characteristics}

Staff from the PCCs expressed concerns that the application might not be very useful and that there would be few opportunities for usage, due to the separate homecare organisation that results in few homecare visits in primary care. There were also concerns that the management of the application would create additional tasks that there would not be any time for. "We might not have time for the increased administration in the beginning."

\subsubsection{Experiences of the intervention}

The concerns were mostly fulfilled, but other issues were also experienced related to e.g. the support within the organization. 
When the staff had used the mobile tool for some time they considered that it would be more useful with additional homecare visits.

If I was to have homecare visits a whole day, day after day, then I absolutely think it would be good to be able to do all documentation immediately. Then I think it really would improve patient safety.

\section{Networks and communications}

The responsibility for support functions were considered to be unclear by many of the participating healthcare professionals. "But I don't really know where to turn for help when it doesn't work. Therefore I have unfortunately not used it for more than a month." Another person stated, "Well, then you feel a little like; who can you ask?!"

Implementation climate

In many ways the implementation of the mobile tool did not really change the healthcare professionals' perceptions of their work, "It's simply a new technology for the same job."

\subsection{Characteristics of individuals}

As previously described, there were some differences in the tolerance for challenges between different users. Some persisted and continued using the mobile tool despite difficulties, whereas others stopped using it. The categories related to this dimension are presented in Fig. 6.

\subsubsection{Expectations before the implementation}

Before the implementation started, users had some concerns but were also eager to start testing the tools, which they had waited for quite some time.

\section{Knowledge and beliefs about the intervention}

Healthcare professionals expressed some concerns regarding how the mobile tool would influence their relationship to the patients, worrying that the technology would steal time and focus from the patient. They expressed that "there might be too much focus on technology during the visits", and that there could be a "risk for less contact with the patient if the tablet takes more time". Another concern described was that you might become too dependent on the technology;

"To become dependent on the tablet, and then when it breaks down you don't know what to do."

In addition to the more general concerns regarding technology's impact on their work, the participants also expressed a concern that the technology would never be ready to use, or that the functions would be reduced so much that the system would become unusable. 
There were variations in the healthcare professionals' expectations before implementation. Some were confident that they would be able to use it, others were a bit more hesitant and stressed that daring to start using it would be important; "one way is to just start using the tablet, perhaps it'll go better than we think..."

\section{Individual stage of change}

Similarly, the individual stage of change or readiness to start using the technology varied. Most were eager to start testing the mobile tools, and just see what happens;

To dare to start using it and see what happens. I think you can find several ways of using the tablet. You can find all sorts of online services [mentions Swedish e-health services such as the national patient portal, portals for ordering materials, online prescription tools]. And perhaps you can help the patient to find the patient portal [1177.se] by using the tablet.

There were clear differences between the contexts though, where those who had been involved from the start were more positive and eager, having waited a long time for the pilot to start, whereas the others were more hesitant.

\section{Individual identification with the organization}

An issue raised only during the pre-implementation focus groups, were concerns regarding the personal responsibility for the devices. Participants worried that they might forget the tablet at the patient's home, or drop it and break the screen, and that this could be either a waste of resources for the organization or that they would personally be responsible for the costs.

\subsubsection{Experiences of the intervention}

Although the participants' characteristics did not necessarily change during the implementation, their selfefficacy and beliefs about the intervention appear to have been affected.

\section{Knowledge and beliefs about the intervention}

The study participants remained positive that this type of intervention could provide benefit, e.g. by making work processes more time efficient and improving patient safety. One of the participants who had used the tool the most said "I don't have to prepare, which usually takes 5 minutes, to print e.g. the list of medications, and the latest lab results". Care planning in the patients' home was also experienced as more efficient; "I can finish it at the patient's home, with the patient. You can discuss what to do next, and then that's done."

Being able to finish tasks while in the field was also experienced as reducing the risk for tasks being forgotten or information lost. "[...] and for the patients and the staff [at the nursing home], that they don't 
have to remind me, 'did you remember that? now this hasn't arrived, why not?', 'oh, I didn't order that, I forgot, or I didn't see the note...'. It feels more organized."

However, the unreliable technology required a lot of patience and persistence of the healthcare professionals.

The biggest challenge has been not to lose your patience. It's like well, now it doesn't work. I have to try the next time again, and the time after that. And that has been difficult since I usually only do this kind of work once a week, so it has been a challenge to not just give up but to instead try and try again.

Only the most enthusiastic users had the patience to keep trying despite the unstable technology. The other users, and especially those who worked in the MHCO, gave up at the first hurdle and ended up not using the mobile tool at all.

Another limitation was that the mHealth app did not fully support the users' needs and several of the participants stated that the mHealth app needed further development and additional functions "Honestly, it feels undeveloped. Several things are missing, like the medication list and $x$-ray results, which are also quite important when you're in the patient's home."

\section{Self-efficacy}

Unstable technology also affected the healthcare professionals' sense of professionalism and could be a cause for embarrassment in front of patients:

It feels embarrassing when it doesn't work when you use the tablet. I can live with that, but it's a little embarrassing. Then it would've been better not to have it [the mobile tool]

One of the healthcare professionals had problems using the mobile tool in the presence of the patient's relatives "that makes me really stressed, because the technology is new to me. When five people ask me questions at once. I haven't been able to handle that. [regarding not being able to find the information on the mobile tool]."

Those who did use the mobile tool found that it improved work processes, patient safety, credibility and work satisfaction.

What's been very positive is that I can finish my work in the patient's home. I know that I won't forget anything. The patient won't be left without his or her medications, so I think that's good. Because it has been stressful before, I haven't always had the time to finish the work immediately when l'd returned to the workplace... so, I find it to be satisfactory as well, to be able to finish the job and not have any loose threads.

They also felt confident in using the mobile technology "It's been good. It's easy to connect and I think it works well. I've actually not experienced any challenges". However, there was a large discrepancy 
between the two contexts and most of the healthcare professionals in the municipality homecare organization did not use the mobile tool at all.

Individual stage of change

As stated above, not all of the healthcare professionals used the mobile tool "I may have a maximum of five [patients]. And then I might as well remember that information or make some notes until I dictate [the record entries]". One reason why it was not used was that the users were not used to this way of working. In some cases, the users did not like how record entries were presented;

"I could edit the record entries later if I only write a few key words [while in the patient's home]. But I don't know, I don't find the entries aesthetically appealing. I think they look much better when I do it the way I usually do."

In other cases, they had no prior experience of writing directly in the medical record, being used to dictating all record entries "Well, I don't really have that much experience. I know how to use the iPad, but it feels like I only use it to read record entries, not to write them myself. I usually don't [write record entries] and I don't do it here either."

The users believed that there were other possible areas where the mobile tool could be useful, but that it creates a need for new knowledge and a necessity to find new fields of application;

Personally I think it's more that you don't have enough imagination. You need to come up with other examples of what you can use it for as well. You just have to use it more and discover even better ways of using it.

It was believed that it would be beneficial to use the mobile tool regularly instead of intermittently in order to really utilize the mobile tool's potential "If I had to use this every day, then maybe I would become more comfortable with using it as well".

\subsection{Process}

The process of implementation was not addressed in the interviews with healthcare professionals, as this was not the main focus of the original project. We will reflect on the implementation process in the discussion.

\section{Discussion}

The implementation of the mHealth application was unsuccessful. The main reason for the unsuccessful implementation was that the application did not sufficiently support the users' needs, but the fact that the technology was immature and the technical infrastructure unstable also contributed.

Prior to the implementation the healthcare professionals had great expectations that the application would facilitate work processes and reduce cognitive workload by allowing real time access to 
information. There were also concerns, mainly due to prior experiences of poor internet connectivity, immature and unstable technology, but also that the application might increase the workload, steal time and focus from the patient and that the project would amount to nothing. Ultimately, both expectations and concerns were confirmed.

Some of the users, especially those who had been involved in the development of the mHealth app, did find that the application added extra value, despite the missing functions, and kept trying time after time, undeterred by the immature technology. Users who worked in the MHCO however, who had not been involved in the design process, gave up at the first hurdle and ended up never using the mobile tool at all. End-user involvement in the design process, often referred to as participatory design [20]-[22], has proven to be essential in both ensuring that the software meets the end-users needs and supports their work processes, and increases acceptance among the users [23], [24]. In addition to the difference in participation during the development process, the second group also used another EHR system in their daily work that was not integrated with the mobile system. The benefit of being able to at least begin documentation in the patients' home was therefore lost to them, further lowering the incentives for them to engage with the system. Lack of interoperability and integration between eHealth system has previously been identified as an important barrier to successful implementation [14]. Physicians who made few home visits, and used dictation for EHR documentation in their everyday work, found the $\mathrm{mHealth}$ app less useful. Again, the importance of ensuring that all potential end-users perspectives are captured in the design process was highlighted [25].

There are several lessons to be learned from this. Firstly, that outcome is dependent on context and secondly, that user engagement is crucial for a successful implementation. We found that the main reasons for the unsuccessful implementation in the MHCO was that the application did not meet their needs, since they mainly worked with another EHR, and that they had not been adequately involved or engaged in the development and implementation process. Here both lack of user involvement [23], [26], and poor interoperability [6], [14] had a negative impact on the acceptability of the system, both contributing to a system that did not support the users work processes [27]. The lengthy development and implementation process also affected user engagement negatively. Studies of user involvements relationship with user satisfaction have however indicated that user involvement can actually overcome frustration from delays and prolonged projects [23], but this was not the case here. Additionally, for less engaged staff, the threshold to start using a new technology was high, and they also had a greater need for additional support, whereas champions kept trying regardless, and often found new areas of use for the technology.

The challenges described by the users in this study are confirmed in other studies and reviews as well. Areas of user involvement, interoperability, reliability of connection and technology and infrastructure are some challenges stated to be either the facilitator if considered in the implementation of eHealth tools, or the barrier if not considered [15]. In a review on 43 studies of mHealth implementation experiences from primary healthcare services the main results were that health workers appreciated mHealth when it improved feedback, speed and workflow [17]. Challenges stated was that mHealth sometimes created 
more work resulting in that some preferred paper instead. Some health workers found the decision support opportunities useful and others thought it threatened their clinical skills [17]. The aspect on workflow was found substantial for the success or failure of eHealth interventions and in particular if workload increased, if workflow was interrupted and if there was an alignment with clinical processes [15].

\subsection{CFIR suitability for mHealth implementation}

CFIR is developed to study processes of implementations, not specifically new technology, and since the effect of an implementation of new technology is dependent on the new technology's functionality, some important aspects of the framework are missing, specifically regarding the technical infrastructure. Hence, we chose to include that in the domain Outer setting. More specific focus on usability of the eHealth or mHealth intervention could also be included under intervention characteristics, but we chose to make use of the "design quality" category here.

The implementation process is vital for the outcome of an implementation and for a successful implementation all stages of the implementation must be properly executed. Our study was not originally designed to study the implementation process and subsequently, material on some aspects of the implementation process is missing since no questions regarding those aspects were asked in the interviews. We see however, that the implementation of the mobile tool most likely would have benefitted from better planning, execution, support functions and resources. When implementing complex interventions, feasibility and pilot studies are essential [28]. This is especially important when implementing mHealth or eHealth where lack of usability is often the cause for failed implementations [29]. For studies of new technology, this could be further specified in the CFIR dimension "process". A specific challenge when implementing an mHealth application in a rural homecare area, was the physical distance between units, and the challenges in keeping day-to-day contact with and providing support to the healthcare professionals. The need for a specific facilitator role was apparent, as is also stressed in other implementation theories, e.g. the PARIHS framework [30]. The distance, both physical and organizational, between the healthcare professionals in the study setting and the centralized ITdepartment responsible for IT-support and trouble-shooting also proved problematic.

The NASSS (non-adoption, abandonment, scale-up, spread, and sustainability) framework, also aims to explain success and failure of implementation of health technology, and to help guide future implementations [31]. The framework includes questions in 7 domains: the condition or illness, the technology, the value proposition, the adopter system (comprising professional staff, patient, and lay caregivers), the organization(s), the wider (institutional and societal) context, and the interaction and mutual adaptation between all these domains over time [31]. In the case described here, the NASSS framework could potentially have been useful in highlighting complexities in the organization of homecare, and the contextual factors that would impact on the usefulness of the system. 
There is a strong belief that eHealth and the introduction of new technology have the potential to revolutionize healthcare and that it will be necessary for healthcare and primary care in the future [32]. The introduction of new technology however often fails [15], [29] and there is a risk that premature implementation of new technology will exhaust healthcare professionals for future projects and implementation. The challenges and concerns raised must be considered to move forward successfully [13]. In both the CFIR [18] and i-PARIHS [30] frameworks, the individuals' previous experiences and beliefs about the intervention will have an impact on the implementation success. When healthcare professionals are exposed to immature digital solutions with poor usability, we may risk a negative impact also on future implementation and innovation projects. To avoid this, we conclude that it is important to ensure that a new technology has the necessary functionality and stability prior to implementation, and that there are routines in place in the organization to guide decision making and implementation processes.

\section{Conclusions}

We conclude that new technology must be sufficiently stable before implementation and have the desired functionality for an implementation to be successful. The functionality of a new technology must support the users' needs and be sufficiently integrated with other IT-systems in the healthcare organization. Even though the execution of the implementation process is important, the implementation will not be successful if the new technology does not properly support the users' needs. In the case presented here, the implementation failed because the technology was unstable and therefore unreliable, not sufficiently supportive of the users' needs and not adapted to the users' workflow. There were however, positive experiences too, and mHealth still has a strong potential to support healthcare professionals work in homecare. In order to achieve this potential, we have to ensure that sufficient resources are allocated to both design and development, evaluation and feasibility studies, and support and engagement during the implementation of mHealth in the future.

\section{Abbreviations}

CFIR

Consolidated Framework for Implementation Research

\section{EHR}

Electronic Health Records

MHCO

Municipality Homecare organization

PCC

Primary Care Center

SKR

The Swedish Association of Local Authorities and Regions 


\section{Declarations}

\section{Ethics approval and consent to participate}

Ethical approval was granted from the Research Ethics Committee at Karolinska Institutet (DNR 2015/1457-31/5).

All participants have given written, informed consent prior to inclusion.

\section{Consent for publication}

Not applicable

\section{Availability of data and materials}

The datasets used and analysed during the current study are available from the corresponding author on reasonable request.

\section{Competing interests}

The authors declare that they have no competing interests.

\section{Funding}

This work has received funding from Innovationsfonden [DETALJER], FORTE - the Swedish Research Council for Health, Working Life and Welfare supports "MobEVAL" (2017-01962), and AFA Försäkring "ePrlm" (190210).

\section{Authors' contributions}

$\mathrm{MH}$ and $\mathrm{LJH}$ were responsible for the design of the study. LJH together with two master students collected the data. $\mathrm{LJH}$ and $\mathrm{MH}$ did the initial analysis of the data. $\mathrm{LJH}, \mathrm{MH}$ and $\mathrm{HH}$ did the final interpretation of the data. All authors contributed in writing, reading and approving the final manuscript.

\section{Acknowledgements}

We would also like to thank Gabor Revay and Richard Scholvin at the Department of eHealth and IT, Stockholm County Council, Health Care Service, Sweden for their support and work in the project.

\section{References}

[1] G. Lanzieri, "Long-term population projections at national level," Statistics in Focus, Eurostat, vol. 3/2006. Eurostat, 2006. 
[2] M. Cabrera, J.-C. Burgelman, M. Boden, O. da Costa, and C. Rodrígues, "eHealth in 2010: Realising a Knowledge-based Approach to Healthcare in the EU - Challenges for the Ambient Care System," Report on eHealth related activities by IPTS, no. Technical Report EUR 21486 EN. Institute for Prospective Technological Studies, 2004.

[3] SKL, "Så möter vi vårdens utnaningar \#vivässarvälfärden [In Swedish]," 2016.

[4] L. Jerlvall and T. Pehrsson, "eHälsa i Landstingen. Maj 2017. Inventering på uppdrag av SLIT-gruppen (In Swedish)," 2017.

[5] L. Lind, E. Sundvall, D. Karlsson, N. Shahsavar, and H. Åhlfeldt, "Requirements and prototyping of a home health care application based on emerging JAVA technology," Int J Med Inf., vol. 68, no. 1-3, pp. $129-139,2002$.

[6] M. Hägglund, I. Scandurra, and S. Koch, "Studying intersection points - an analysis of information needs for shared homecare of edlerly patients," J. Inf. Technol. Healthc., vol. 7, no. 1, pp. 1-20, 2009.

[7] S. Koch, M. Hägglund, and I. Scandurra, Informatics and Socio-Technical Challenges when Designing Solutions for Integrated eCare, vol. 1. 2017.

[8] M. Hägglund, I. Scandurra, and S. Koch, "Supporting citizen-centered care for seniors - Experiences from two Swedish research projects," in Proceedings - IEEE Symposium on Computer-Based Medical Systems, 2012.

[9] World Health Organization, "mHealth: New horizons for health through mobile technologies: second global survey on eHealth.," Geneva, 2011.

[10] “E-hälsa och välfärdsteknik i kommunerna 2017 [in Swedish], 2017.

[11] R. M. J. J. van der Kleij et al., "SERIES: eHealth in primary care. Part 1: Concepts, conditions and challenges," Eur. J. Gen. Pract., vol. 25, no. 4, pp. 179-189, Oct. 2019.

[12] Socialdepartementet, “Vision e-hälsa 2025,” 2016.

[13] U. Öberg, C. J. Orre, U. Isaksson, R. Schimmer, H. Larsson, and Å. Hörnsten, “Swedish primary healthcare nurses' perceptions of using digital eHealth services in support of patient self-management.," Scand. J. Caring Sci., vol. 32, no. 2, pp. 961-970, Jun. 2018.

[14] M. R. Lennon et al., "Readiness for Delivering Digital Health at Scale: Lessons From a Longitudinal Qualitative Evaluation of a National Digital Health Innovation Program in the United Kingdom," J Med Internet Res, vol. 19, no. 2, p. e42, 2017.

[15] C. Granja, W. Janssen, and M. A. Johansen, "Factors Determining the Success and Failure of eHealth Interventions: Systematic Review of the Literature," J Med Internet Res, vol. 20, no. 5, p. e10235, 2018. 
[16] H. M. James, C. Papoutsi, J. Wherton, T. Greenhalgh, and S. E. Shaw, “Spread, Scale-up, and Sustainability of Video Consulting in Health Care: Systematic Review and Synthesis Guided by the NASSS Framework.," J. Med. Internet Res., vol. 23, no. 1, p. e23775, Jan. 2021.

[17] W. A. Odendaal et al., "Health workers' perceptions and experiences of using mHealth technologies to deliver primary healthcare services: a qualitative evidence synthesis.," Cochrane database Syst. Rev., vol. 3, no. 3, p. CD011942, Mar. 2020.

[18] L. J. Damschroder, D. C. Aron, R. E. Keith, S. R. Kirsh, J. A. Alexander, and J. C. Lowery, "Fostering implementation of health services research findings into practice: a consolidated framework for advancing implementation science," Implement. Sci., vol. 4, no. 1, p. 50, Aug. 2009.

[19] U. H. Graneheim and B. Lundman, "Qualitative content analysis in nursing research: concepts, procedures and measures to achieve trustworthiness," Nurse Educ. Today, vol. 24, pp. 105-112, 2004.

[20] A. Kushniruk and C. Nøhr, "Participatory Design , User Involvement and Health IT Evaluation," in Evidence-Based Health Informatics, E. Ammenwerth and M. Rigby, Eds. IOS Press, 2016, pp. 139-151.

[21] D. Schuler and A. Namioka, "Participatory Design - principles and practices." Lawrence Erlbaum Associates, New Jersey, 1993.

[22] S. Bødker and O. Iversen, "Staging a Professional Participatory Design Practice - Moving PD beyond the Initial Fascination of User Involvement," NordiCHI 2002. October 19-23, Aarhus, pp. 11-18, 2002.

[23] M. Bano, D. Zowghi, and F. da Rimini, "User satisfaction and system success: an empirical exploration of user involvement in software development," Empir. Softw. Eng., vol. 22, no. 5, pp. 23392372, 2017.

[24] M. Berg, "Implementing information systems in health care organizations: myths and challenges," Int. J. Med. Inform., vol. 64, no. 2-3, pp. 143-156, 2001.

[25] I. Scandurra, M. Hägglund, and S. Koch, "From user needs to system specifications: Multi-disciplinary thematic seminars as a collaborative design method for development of health information systems," $J$. Biomed. Inform., vol. 41, no. 4, 2008.

[26] I. Scandurra, M. Hägglund, and S. Koch, "Application of the multi-disciplinary thematic seminar method in two homecare cases - A comparative study," in Studies in Health Technology and Informatics, 2008 , vol. 136.

[27] S. Rosborg, M. Lindberg, M. Ramukumba, L. Jäderlund Hagstedt, and M. Hagglund, Exploring mHealths Fit to Workflow in Homecare a A Case Study in Sweden, vol. 265. 2019.

[28] P. Craig, P. Dieppe, S. Macintyre, S. Michie, I. Nazareth, and M. Petticrew, "Developing and evaluating complex interventions: the new Medical Research Council guidance," BMJ, vol. 337, p. a1655, Sep. 2008. 
[29] M. Berg, "Patient care information systems and health care work: a sociotechnical approach," Int J Med Inf., vol. 55, no. 2, pp. 87-101, 1999.

[30] G. Harvey and A. Kitson, "PARIHS revisited: From heuristic to integrated framework for the successful implementation of knowledge into practice," Implement. Sci., vol. 11, no. 1, 2016.

[31] T. Greenhalgh et al., "Beyond Adoption: A New Framework for Theorizing and Evaluating Nonadoption, Abandonment, and Challenges to the Scale-Up, Spread, and Sustainability of Health and Care Technologies.," J. Med. Internet Res., vol. 19, no. 11, p. e367, Nov. 2017.

[32] C. A. Meier, M. C. Fitzgerald, and J. M. Smith, "eHealth: extending, enhancing, and evolving health care.," Annu. Rev. Biomed. Eng., vol. 15, pp. 359-382, 2013.

\section{Figures}

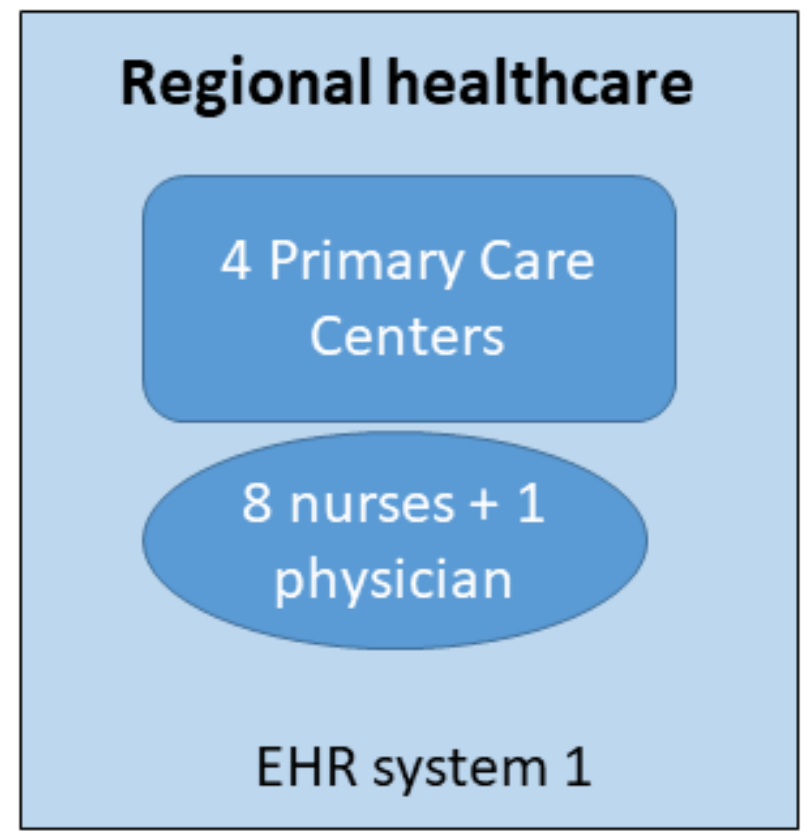

\section{Municipality healthcare}

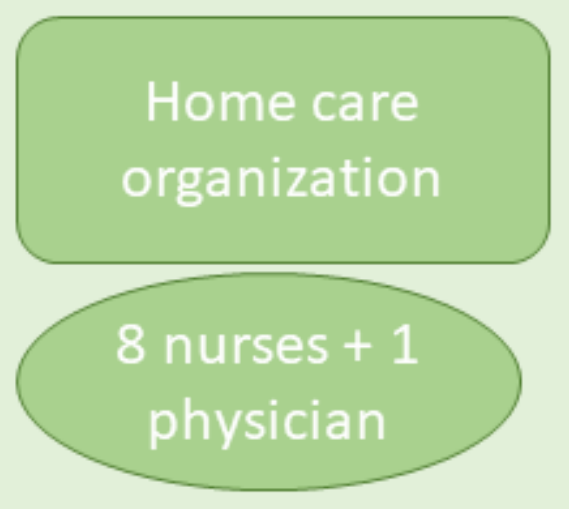

EHR system 2

Figure 1

Study setting 


\section{Consolidated Framework of Implementation Research (CFIR)}

\section{Intervention characteristics}

- Intervention source

- Evidence strength and quality

- Relative advantage

- Adaptability

- Trialability

- Complexity

- Design quality

- Cost

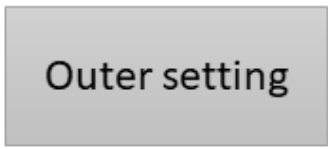

- Patients needs and resources - Cosmopolitanism

- Peer pressure - External policies and incentives

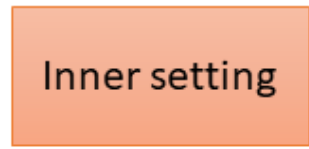

- Structural characteristics

- Networks and communication

- Culture

- Implementation climate

\section{Characteristics of individuals}

- Knowledge and beliefs about the intervention

- Self-efficacy

- Individual stage of change

- Individual identification with organization - Other personal attributes

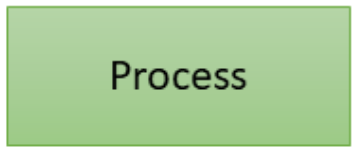

- Planning

- Engaging

- Executing

- Reflecting and evaluating

\section{Figure 2}

An overview of the CFIR framework 


\section{Intervention characteristics}

\section{Expectations before implementation}

\section{Relative advantage}

- Reduction of cognitive workload

- Time efficient and timely

- Real time access to information

- Lack of information and functionality

\section{Complexity}

- Increased complexity and double documentation with many mobile apps

- Work arounds to adapt to the system may increase cognitive workload

\section{Design quality}

- Slow and frustrating

- Immature and unstable

\section{Experiences after use}

\section{Relative advantage}

- Reduction of the cognitive workload

- Finish work on site

- No need for reminders

- $\quad$ Access to important functions \& information

- Missing functions

- Reduces unnecessary lab tests \& orders

- Note formatting is worse

\section{Complexity}

- Adaptations of work processes are required

- Condensed documentation

- Preliminary documentation on site

\section{Design quality}

- Poor design/unclear layout

- Design improved during the project

- Immature and unstable

\section{Figure 3}

Intervention characteristics 


\section{Outer setting}

Expectations before implementation

\section{Technical infrastructure}

- Previous experiences among the staff with poor Internet connectivity in the homecare areas caused worry

Patient needs and resources

- Healthcare professionals looked forward to being able to use the mobile device as a tool for learning and patient communication.

- Being able to answer the patients' questions immediately
Experiences after use

\section{Technical infrastructure}

- Poor Internet connectivity

Patient needs and resources

- Supports better work processes and improves patient safety

- Facilitates patient participation

\section{Figure 4}

Outer setting. 


\section{Inner setting}

Expectations before implementation

\section{Structural characteristics}

- Concerns that there will be no time to do the additional tasks to manage the system

- Concerns that lack of homecare visits will make the system less useful and rarely used
Experiences after use

\section{Structural characteristics}

- With more homecare visits the need for the system will increase

Networks and communications

- Unclear responsibility and support functions Implementation climate

- Same job, new technology

Figure 5

Inner setting. 


\section{Characteristics of individuals}

\section{Expectations before implementation}

Knowledge and beliefs about the intervention

- Concerns that the technology will steal time and focus from the patient

- Concerns of becoming too dependent on the technology

- Concerns that the project will amount to nothing

\section{Self-efficacy}

- To dare to try the new technology

Individual stage of change

- Looking forward to getting to test

Individual identification with organisation

- Worry about personal responsibility for the devices

\section{Experiences after use}

\section{Knowledge and beliefs about the} intervention

- Positive that this type of intervention could provide benefit

- Unreliable technology has required patience and persistence

- Needs further development and additional functions

\section{Self-efficacy}

- Embarrassing when technology does not work

- Improved work processes improve patient safety, credibility, and work satisfaction

- Confidence in using mobile technology Individual stage of change

- Not used to this way of working

- Creates a need for new knowledge

- Have not used the technology

Figure 6

Characteristics of individuals.

\section{Supplementary Files}

This is a list of supplementary files associated with this preprint. Click to download.

- Additionalfile1.docx

- Additionalfile2.docx

- Additionalfile3.docx 